\title{
Short-term outcomes and long-term impact of a programme in medical education for medical students
}

\author{
Pamela B Andreatta, ${ }^{1}$ Miranda L Hillard, ${ }^{2}$ Margaret Ann Murphy, ${ }^{1}$ Larry D Gruppen ${ }^{1}$ \& Patricia B Mullan ${ }^{1}$
}

OBJECTIVES There is growing appreciation of the value of early preparation of future medical educators. Staff development programmes, conferences and workshops pertaining to the training of educators may be crucial to the pursuit of a school's larger educational mission to educate students, doctors and scholars and to provide comprehensive knowledge, research, patient care and service. This study examined the efficacy of a 1-week educational intervention aimed at preparing medical students to become effective doctor educators by building skills early in their careers. The study asked whether participation in a 5-day teacher training programme led to increased knowledge of instructional methods, more favourable attitudes towards teaching, and the integration of structured instructional design methods in a student-developed teaching project.

METHODS A mixed methods research design was employed with quantitative data captured through pre- and post-test inventories, qualita- tive components captured through written comments, and a 2-year post-intervention survey. Quantitative analyses included pre-/postintervention repeated measures with calculated effect sizes. Qualitative analysis was conducted using constant comparative methods.

RESULTS Subjects demonstrated improved content knowledge and more positive attitudes towards motivation, teaching confidence, teacher roles, varied pedagogy, and use of assessment, instructional planning, and evaluation. Subjects were able to incorporate the programme's teaching theory and methods into their teaching projects and assessment of peers' and others' teaching in their own institutions 2 years post-training.

CONCLUSIONS This study demonstrates that a well-designed programme for teacher preparation can be pedagogically effective for training medical students to become better educators and that this learning can be incorporated into long-term practice.

KEYWORDS *education, medical, undergraduate; *teaching; *students, medical; *attitude of health personnel; professional competence/*standards; professional role; motivation; Michigan.

Medical Education 2009: 43: 260-267

doi:10.1111/j.1365-2923.2008.03273.x

${ }^{1}$ Department of Medical Education, University of Michigan Medical School, Ann Arbor, Michigan, USA

${ }^{2}$ University of Toledo College of Medicine, Toledo, Ohio, USA
Correspondence: Pamela B. Andreatta, Department of Medical Education, Clinical Simulation Center, University of Michigan, G1105 Towsley Center, Box 5201, 1500 East Medical Center Drive, Ann Arbor, Michigan 48109-5201, USA. Tel: 001734615 0273; Fax: 001734936 1641; E-mail: pandreat@umich.edu 


\section{INTRODUCTION}

Changes in medical education have increased teaching demands on medical school faculty and residents, yet doctors receive little formal training in preparing and facilitating instruction. ${ }^{1,2,23}$ Advocates for change in medical education encourage the use of myriad pedagogical approaches, but how and when faculty members learn the requisite skills to prepare effective instruction is unclear. Teaching abilities have profound impact on learner outcomes and can be improved through training in instructional processes and techniques. ${ }^{3-7}$ The challenges involved in the preparation of medical educators lie in identifying the critical content of such preparation and its appropriate location in the curriculum. Some residency programmes offer seminar-type training in the 1-minute preceptor model ${ }^{8,9}$ and others offer shortcourses on concepts associated with good teaching. ${ }^{410-15}$ Shorter courses provide an awareness of the challenges of teaching and exposure to specific tools that can be used to support instruction, but they do not allow for the level of conceptual integration and confidence-building learners require to comprehensively apply these concepts. ${ }^{2}$ In a recent study, Smith $e t a l .^{7}$ reported successful outcomes with a version of the 'Training Tomorrow's Teachers Today' programme. Their version of the programme emphasised teaching techniques and leadership skills related to institutional change. Their experience demonstrated the feasibility and acceptability of working with interested medical students to enhance leadership and teaching skills in a 1-week programme. ${ }^{7}$ Our programme retained the medical student-led session on institutional change, but included more structured approaches to teaching skills, and added material on the underpinnings of educational theory, motivation, and structured curriculum planning and design that are critical to measurable instructional outcomes. We also augmented the scope of teaching contexts to include approaches to teaching psychomotor skills and approaches to the design of medical education that accommodate learners at different stages of training.

In our study, we sought to answer the following research questions:

1 Does participation in a 5-day teacher training conference lead to increased knowledge of instructional methods?

2 Do subjects' attitudes towards their teaching (teacher confidence, pedagogical approach, motivational factors, uses of assessment and evaluation, instructional planning, and teaching roles and responsibilities) change as a result of participation in the conference?

3 Do subjects incorporate acquired knowledge when constructing their own teaching modules?

4 Do subjects incorporate acquired knowledge when providing feedback about their peers' teaching?

5 Do subjects go on to incorporate acquired knowledge in their medical careers?

\section{METHODS}

Medical students $(n=13)$ interested in a career in academic medicine applied to participate in a conference entitled 'Training Tomorrow's Teachers Today' (T4). The T4 conference was conceived by the American Medical Student Association, with an earlier version targeting presentation and leadership skills. ${ }^{7}$ The T4 curriculum offered by our institution, the Department of Medical Education, University of Michigan Medical School, was revamped to focus on the underpinnings of learning and instruction, in addition to providing structured approaches for teaching different modalities (e.g. psychomotor skills) and accommodating learners at different stages of medical education. Applications were received from medical students across the nation. Selection was based on the applicant's demonstrated interest in teaching, leadership experience and a letter of support from his or her dean.

Subjects convened at the University of Michigan to participate in the 1-week conference. The studentcentred, project-oriented training was led by a team of university medical school faculty staff from the departments of internal medicine, paediatrics, surgery, psychiatry and medical education. Content sections included: educational psychology; motivation; small-group instruction; psychomotor skills; simulation and standardised patients; didactic and large-group instruction; feedback; reflective practice; instructional design; teaching techniques; classroom management; assessment and evaluation; programme administration; educational research, and educational leadership. Subjects were provided with a binder of content materials and resources to aid in the instructional processes, and a master schedule to guide their progress throughout the week (Table S1).

Throughout the programme, students devised, piloted and evaluated a teaching project for 
implementation at their respective medical schools. One-quarter of the conference sessions and all homework assignments were devoted to preparing the project. Most session activities related specifically to facilitating the transfer of knowledge from content sessions to the projects. These activities included discussing ideas, individual mentoring by faculty, constructing teaching plans, securing materials and setting up the practice teaching sessions. The students were each allotted 15 minutes to pilot their teaching projects to their peers, faculty and a group of undergraduate students pursuing medical careers. All student teaching sessions were video-recorded and a DVD and written summary of faculty and peer feedback were given to each subject. This provided all subjects with a record of individual and collective projects for future reference.

We used a four-component, mixed-method assessment protocol to evaluate the programme's impact on teaching knowledge, skills and attitudes. Measuring the prevalence of a known attribute, such as an attitude, can be accomplished through quantitative methods. However, when seeking to explain how knowledge of teaching is transmitted, absorbed and transformed into a part of one's identity, using qualitative methods further elucidates the construct and provides supplemental and detailed richness to the analysis. ${ }^{16,17}$

Faculty and peers reviewed projects using a 13-item checklist scored with a 5-point Likert scale ( $1=$ strongly disagree, $5=$ strongly agree) to assess instructional methods, strategies and the teaching abilities of their peers. They were also asked to respond to the questions:

1 What did you learn from this session?

2 What were the best parts of the session?

3 What other comments or feedback do you have for this session?

The results of the peer assessments provided two components for evaluating the effectiveness of the T4 conference, namely, the students' ability to apply acquired knowledge to, firstly, their project, and, secondly, substantive critique of their peers' projects. We analysed peer and faculty assessments of student projects using descriptive statistics for ratings and qualitative analyses for comments.

In their systematic review of programmes to improve medical teaching effectiveness, Steinert $e t$ al. ${ }^{18}$ cite the under-utilisation of qualitative methods for evaluation. Qualitative methods deepen understanding of complex processes that are not well understood, such as how knowledge is transferred in applied psychosocial contexts like teaching. Peer comments were interpreted through the constant comparison method of theme generation and searching for counter examples. ${ }^{19-21}$ Three reviewers categorically coded the comments.

The third programme evaluation component was comprised of pre- and post-training assessments. The assessment instrument consisted of 30 items examining attitudes using a 5-point Likert scale $(1=$ strongly disagree, $5=$ strongly agree $)$, and 19 open-ended, knowledge-based items from the content domain. Three independent experts established content validity through systematic review, modification and approval. Repeated measures analyses with calculated effect sizes were used to identify significant differences between the pre- and post-training assessments $(P<0.05)$.

A fourth programme evaluation component involved assessment of whether subjects were able to incorporate acquired knowledge in their medical careers. We surveyed subjects 2 years later to assess what information students had retained, if students had applied this knowledge to their medical careers, if the programme had increased awareness of teaching methods used by others, and how it had prepared the participants as medical educators. The 2-year follow-up responses were transcribed and analysed thematically to reveal how subjects had applied T4 knowledge to the broader context of their medical careers. Selected interview responses were extracted to illustrate the main emergent themes.

\section{RESULTS}

We found a significant difference between pre/posttraining knowledge assessment $\left(\right.$ mean $_{\text {pre }} 7.69$ [SD 0.92]; mean $_{\text {post }} 33.39$ [SD 1.51]). The large effect size of $\eta^{2}=0.96$ demonstrates a substantial increase in the students' knowledge of instructional methods following the conference. Strong effect sizes were found for students' attitudes about motivation factors, teaching confidence and assessment as integral factors in instruction (Table 1). Moderate effect sizes were achieved in subjects' attitudes about instructional planning, use of evaluation in curricular design, role of the teacher in the instructional process, and value of variable pedagogy. Effect size interpretations are based on Cohen's recommendations. ${ }^{22}$ 
Table 1 Change in mean attitudes about teaching*

\begin{tabular}{|c|c|c|c|}
\hline Teaching dimension & $\begin{array}{l}\text { Mean }_{\text {pre }} \\
\text { (SD) }\end{array}$ & $\begin{array}{l}\text { Mean }_{\text {post }} \\
\text { (SD) }\end{array}$ & $\begin{array}{l}\text { Effect } \\
\text { size } \eta^{\dagger}\end{array}$ \\
\hline Motivation factors & $2.92(0.24)$ & $4.31(0.18)$ & $0.73^{\S}$ \\
\hline Teaching confidence & $3.10(0.19)$ & $4.08(0.12)$ & $0.71^{\S}$ \\
\hline Assessment factors & $2.27(0.10)$ & $3.08(0.20)$ & $0.65^{\S}$ \\
\hline Instructional planning & $3.42(0.20)$ & $4.19(0.11)$ & $0.48^{\S}$ \\
\hline Evaluation factors & $3.69(0.18)$ & $4.08(0.08)$ & 0.28 \\
\hline $\begin{array}{l}\text { Teacher roles and } \\
\text { responsibilities }^{\dagger}\end{array}$ & $2.46(0.22)$ & $2.08(0.14)$ & 0.28 \\
\hline Pedagogical approach & $3.0(0.28)$ & $2.39(0.10)$ & 0.27 \\
\hline \multicolumn{4}{|c|}{$\begin{array}{l}\text { * } 5 \text {-point Likert scale }(1=\text { strongly disagree, } 5=\text { strongly } \\
\text { agree) } \\
+ \text { Inverse coding: a higher score indicates a more autocratic } \\
\text { teaching role } \\
\vdots \text { Inverse coding: a higher score indicates more inflexible } \\
\text { pedagogy } \\
\S P<0.05 \\
S D=\text { standard deviation }\end{array}$} \\
\hline
\end{tabular}

Students were able to incorporate our educational programme content into their teaching projects, with mean peer ratings ranging from 4.04 to 4.74 on a scale of $1-5(1=$ very poor, $5=$ very good $)$. The grand mean of peer ratings for all projects was 4.45 (standard deviation $[\mathrm{SD}]=0.20$ ), with a skewness of -0.722 . Faculty ratings for the teaching projects were slightly lower, ranging from 3.2 to 4.7 . The grand mean of faculty ratings for all projects was 4.06 $(\mathrm{SD}=0.47)$, with a skewness of -0.512 . Both faculty and peers ratings were negatively skewed, indicating that ratings tended towards favourable assessments of the projects. Peer ratings were significantly more skewed towards positive ratings with less variance than the faculty ratings, which is consistent with an expected difference in discriminatory expertise between faculty and peer raters.

Students were also able to incorporate our educational programme content to provide substantive critique of their peers' projects. Three researchers independently identified themes from peer feedback, compared themes and agreed on 12 categories of critique (Table 2). Comments were multi-coded if they overlapped categories. The categorical framework enabled us to identify key concepts and compare them with the curriculum to determine if the conference influenced peer feedback. All subjects incorporated 10 of 12 categories in their projects.
Most subjects provided their peers with comprehensive feedback about specific instructional attributes. All but one category (general praise) directly related to our programme's curriculum.

The follow-up survey, conducted 2 years after the educational programme, achieved a response rate of $50 \%$, with all responders indicating that they applied our educational programme's material to their medical careers, particularly in terms of delivering lectures or talks and developing other educational programmes. For example, one respondent wrote about using knowledge acquired through our programme to develop a programme to teach residents how to teach students during rounds, with a faculty seminar on the same topic in progress.

Another responder remarked that she used specific instructional resources from our programme in her medical education research: 'I used them specifically to help design a nutrition/intuitive eating curriculum for an NIH [National Institutes of Health] interventional study for overweight Latino teenagers. My PI was impressed that I had all of these teaching and planning skills, and I am now helping him look at the data the programme has produced.'

All responders reported that they had increased their awareness of how other people teach, crediting the application of instructional design, planning and learner engagement. For example, one respondent commented on the importance of tying instruction to objectives: 'They [effective teachers] have decided ahead of time what they want learners to gain from their talk. Good teachers have their educational goals laid out. There is forethought there and it [the lecture] seems to make more sense [to the learner].'

Another commented: 'I esp[ecially] notice objective and goal statements, length of presentation, slide colours that put people to sleep, and other "minor" pitfalls. I also notice how some instructors really reach the audience: usually the speaker is particularly dynamic or the session is interactive.'

All responders reported that our educational programme had helped prepare them as medical educators by providing them with tools for instructional planning and teaching. One responder stated: 'I gave a talk last week for GI [gastrointestinal] bleeding. I still have my old notes, and used them to lay out my educational objectives. I have entered an academic medicine programme and there is an expectation of teaching. I've entered with this skill set and it is useful.' 
Table 2 Categories of peer-generated performance feedback, curriculum connection and student implementation

\begin{tabular}{|c|c|c|c|c|c|}
\hline Feedback category & Category description & Category example & $\begin{array}{l}\text { Curriculum } \\
\text { connection }\end{array}$ & $\begin{array}{l}\text { Subjects } \\
\text { included } \\
\text { in project }\end{array}$ & $\begin{array}{l}\text { Subjects } \\
\text { included } \\
\text { in peer } \\
\text { critique }\end{array}$ \\
\hline Organisation & $\begin{array}{l}\text { Module was organised and } \\
\text { planned in a straightforward, } \\
\text { effective manner }\end{array}$ & $\begin{array}{l}\text { 'I thought you had a very simple } \\
\text { and relevant intro-discussion' }\end{array}$ & Yes & $13(100 \%)$ & $13(100 \%)$ \\
\hline Learner engagement & $\begin{array}{l}\text { Modules that directly engaged } \\
\text { the learner through active } \\
\text { participation }\end{array}$ & $\begin{array}{l}\text { 'Exercise served as stimulation } \\
\text { to discussion' }\end{array}$ & Yes & $13(100 \%)$ & $13(100 \%)$ \\
\hline Presentation comfort & $\begin{array}{l}\text { Overriding demeanour of the } \\
\text { presenter and his or her } \\
\text { familiarity with the topic }\end{array}$ & $\begin{array}{l}\text { 'You are very confident in your } \\
\text { presentation; it flowed } \\
\text { seamlessly' }\end{array}$ & Yes & $13(100 \%)$ & $13(100 \%)$ \\
\hline Topic explanation & $\begin{array}{l}\text { Clear transference of content } \\
\text { material to the target audience }\end{array}$ & $\begin{array}{l}\text { 'Dynamics of presentation were } \\
\text { exactly indicative of what you } \\
\text { were trying to teach' }\end{array}$ & Yes & $13(100 \%)$ & $13(100 \%)$ \\
\hline General praise & $\begin{array}{l}\text { Comment that broadly related } \\
\text { praise or imparted general } \\
\text { information to the presenter }\end{array}$ & 'Really terrific session' & No & $13(100 \%)$ & $13(100 \%)$ \\
\hline Activity/demonstration & $\begin{array}{l}\text { Modules that incorporated an } \\
\text { active teaching event with } \\
\text { learner participation }\end{array}$ & $\begin{array}{l}\text { 'The drama was creative and } \\
\text { very useful as an alternative } \\
\text { means for remembering the } \\
\text { sequence' }\end{array}$ & Yes & $13(100 \%)$ & $12(92 \%)$ \\
\hline Instructional techniques & $\begin{array}{l}\text { Modules that incorporated } \\
\text { specific teaching techniques } \\
\text { to facilitate learning }\end{array}$ & $\begin{array}{l}\text { 'Good use of building that } \\
\text { slide! It included good } \\
\text { illustrations that found an } \\
\text { effective way of finding out if } \\
\text { terms needed to be explained' }\end{array}$ & Yes & $13(100 \%)$ & $12(92 \%)$ \\
\hline Humour & $\begin{array}{l}\text { Humour was used to affect } \\
\text { audience demeanour }\end{array}$ & 'Good use of humour...' & Yes & $13(100 \%)$ & $11(85 \%)$ \\
\hline Time management & $\begin{array}{l}\text { Subject utilised efficient and } \\
\text { effective time management } \\
\text { strategies }\end{array}$ & 'Very well paced/organised' & Yes & $13(100 \%)$ & $11(85 \%)$ \\
\hline Supporting materials & $\begin{array}{l}\text { Modules that utilised physical, } \\
\text { material support for the } \\
\text { instruction }\end{array}$ & $\begin{array}{l}\text { 'Loved pictures to describe the } \\
\text { non-verbal' }\end{array}$ & Yes & $13(100 \%)$ & $10(77 \%)$ \\
\hline Energy/enthusiasm & $\begin{array}{l}\text { Subject engaged learners } \\
\text { through his or her energy } \\
\text { and enthusiasm }\end{array}$ & $\begin{array}{l}\text { 'I liked this session - and what } \\
\text { made it fun in light of a heavy } \\
\text { subject was your enthusiasm' }\end{array}$ & Yes & $11(85 \%)$ & $8(62 \%)$ \\
\hline Assessment methods & $\begin{array}{l}\text { Modules that incorporated } \\
\text { learner-assessment activities }\end{array}$ & $\begin{array}{l}\text { 'I thought the activity and the } \\
\text { PowerPoint was a great way to } \\
\text { assess our understanding of } \\
\text { the presentation' }\end{array}$ & Yes & $6(46 \%)$ & $3(23 \%)$ \\
\hline
\end{tabular}

Other comments about how skills acquired during our programme had benefited the students' medical careers included: 'I still have the resources handed out during the conference that I can use in curricular design;' '...the programme gave me tools to be effective in planning and teaching;' '...the 
programme helped me to think of other ways to give patients information,' and '...the programme gave me the basic tools and confidence to instruct in an area in which I'm proficient.'

A connection to the value of a medical education community in professional practice was an important programme outcome, demonstrated by postconference networking between programme participants. Responders mentioned continued contact with peers and faculty as an enduring outcome of the conference, making comments such as: '....also gave me a support network to bounce ideas off of;' '...networking [with] inspiring people (still talk to people I met there),' and '...there are people out there just as excited about the learning process as I am.'

\section{DISCUSSION}

There is growing appreciation for the early preparation of medical educators as part of the pursuit of an institution's larger mission to educate students, doctors and scholars, and to provide knowledge, research and patient care. ${ }^{23,24}$

Our results suggest that our educational programme improved explicit teaching abilities across all assessed dimensions in our sample. Large effect sizes and significant gains in knowledge acquisition and attitudes about motivation in the learning process, instructional assessment and teaching confidence indicate that the students were able to integrate the cognitive and affective domains of teaching. The students reported that these abilities were retained and applied in their career roles.

Improved perceptions of instructional planning probably resulted from the requirement to apply multiple facets of designing, producing, piloting and evaluating a teaching project. Smaller gains in perceptions about pedagogical strategies and curriculum evaluation may in part be attributed to the curriculum design, which included, but did not emphasise, specific elements of goal and task analyses, which are important factors in devising pedagogy and determining valid evaluation methods. After the conference, students viewed learners as being more responsible and empowered within the learning context than they had previously believed. This was probably the result of discussions about teacher and learner roles and the learner-focused methods employed during the programme.
High ratings of the projects with minimal variation may reflect the conformity of conference sessions and the inter-dynamic cohort nature of the pedagogy, but may also indicate a tendency to provide subjectively positive feedback to people whom raters know, like and respect. ${ }^{25}$ The negatively skewed distribution of feedback ratings by both faculty and peers suggests that this mechanism may have been partially in effect. However, qualitative assessment of the feedback provided for each subject showed that all participants utilised knowledge-based skills and integrated affective components of teaching.

A smaller number of subjects $(46 \%)$ employed assessment as part of their project and only $23 \%$ commented specifically on their peers' use of assessment. Given the subjects' expressed attitudes about assessment being integral to instruction, we attribute the lack of assessment in the actual student teaching sessions to the 15-minute time limitation for each project. Several students ran over their allotted time and were required to stop short of their intended teaching plans, which eliminated the opportunity to assess at the end.

Our findings suggest that training provided by our structured educational programme facilitated a comprehensive level of understanding of the curriculum because students were able to apply conceptual constructs to new, original lessons, as well as to integrate knowledge in critiquing teaching projects. These two facets demonstrate the transfer of conceptual knowledge to new and unique applications, which indicates higher-order cognitive integration. These results align with Roberson et al.'s findings that teacher training affects a teacher's choices of instructional methods, instructional arrangement and student-teacher interaction. ${ }^{26}$ That these results persisted at 2 years post-training, with students applying concepts to teaching and programme development later in their careers, is further evidence of deep knowledge structures.

A strength of this study was its use of mixed methods to provide four components of evaluation that together provide a clearer picture of the programme's effect on students than would be possible through pre-/post-test assessment only. Although effects from teacher training workshops have been difficult to show in the past, ${ }^{24}$ we were able to document a pedagogical framework for facilitating medical teacher training with durable results. The use of multiple integrated assessment methods with quantitative and qualitative measures provided a 
more complete evaluation of the conference effectiveness and is suggested for future studies.

A limitation of this study is that the pre- and posttest questions were identical, except for a single open-ended, post-test question. Ideally, pre- and post-test questions should be used in parallel rather than identical forms to reduce potential response effect. However, the cost and time involved in testing parallel pre- and post-test questions for comparability was prohibitive for this small study. The relative lack of pre-existing knowledge on the part of the subjects, as demonstrated by their uniformly poor pre-test performance $($ mean $=7.69 / 46)$, rendered the retention of detailed, content-specific test questions over a 5-day period improbable. Given that the 5 days between test administrations were replete with the abundant provision of new information, strategies, skills and relationships, it is unlikely that the pre-test confounded performance on the identical post-test. That the subjects' post-test scores ranged between $52 \%$ and $85 \%$ is further evidence that the subjects did not learn to the test per se, but rather were able to integrate their knowledge from the curriculum and apply it to the test questions. That said, with a sufficient sample size, validity and reliability evidence would add significantly to the strength of the knowledge-based component of conference evaluation. Certainly pre/post-intervention questions could be tested for validation in the future.

Another limitation of this study is that the subjects were self-selected through their interest in teaching and their motivation to attend the educational programme. This limitation was exemplified by one responder, who commented: 'It's really hard and difficult to find people just as interested and who have the time.' Because all medical educators will teach in some context, future research that focuses on demonstrating conference outcomes with wider, less enthusiastic audiences is merited. The focused and modularised pedagogy of our programme's format is easily transferable to multiple evaluation contexts. For example, one subject reported that she provided our programme's curriculum to her residency programme: 'I have taught my whole internal medicine residency programme, some are receptive, others not so interested. My programme director loved the info/ideas and is planning a seminar for our faculty.' Expansion of the programme curriculum and pedagogy to other programmes and a wider range of learners (residents, faculty etc.) would provide opportunities to assess more comprehensive generalised results.
In summary, we believe that the results of this programme offer important contributions to the broad context of training medical educators. A modularised curriculum format can be easily adapted to meet other programmes of limited duration. We delivered the programme in 5 days, but the modules may be sequenced over a longer time period. The inclusion of fundamental instructional design principals and an applied project requires learners to think deeply about the concept of teaching rather than the mechanics of teaching, and imparts a more robust cognitive framework around the construct. This framework is transferable to training contexts at any institution, such as summer programmes, curriculum breaks or elective components in undergraduate, graduate and continuing medical education programmes, and offers potential solutions for improving the educational vitality of our medical institutions.

Contributors: PBA contributed to the conception and design of the study, research methods, assessment methods and assessment instruments, the acquisition, analysis and interpretation of data, and the writing, revision and review of the manuscript. MLH contributed to data acquisition, analysis and interpretation, and the drafting of the manuscript. MAM contributed to data analysis and interpretation, and the drafting of the manuscript. LDG contributed to the design of the assessment instrument and the revision of the manuscript. PBM contributed to the design of the study, research methods, assessment methods and assessment instruments, data analysis and interpretation, and the revision of the manuscript. All authors approved the final manuscript for publication. Acknowledgements: none.

Funding: this study was funded by the University of Michigan and the American Medical Student Association. Conflicts of interest: none.

Ethical approval: the University of Michigan Institutional Review Board ruled that this research did not require ethical approval.

\section{REFERENCES}

1 Jason H, Westberg J. Preparation for teaching. In: Teachers and Teaching in US Medical Schools. Norwalk, CT: Appleton-Century-Crofts 1982;71-83.

2 Wilkerson L, Irby DM. Strategies for improving teaching practices: a comprehensive approach to faculty development. Acad Med 1998;73 (4):387-96.

3 Harden RM, Crosby J. AMEE Guide No. 20: the good teacher is more than a lecturer - the 12 roles of the teacher. Med Teach 2000;22 (4):334-47.

4 Busari JO, Scherpbier AJ, van der Vleuten CP, Essed GG. A 2-day teacher-training programme for medical 
residents: investigating the impact on teaching ability. Adv Health Sci Educ Theory Pract 2006;11 (2):133-44.

5 Mahler S, Benor D. Short- and longterm effects of a teacher-training workshop in medical education. Higher Educ 1984;13:265-73.

6 Skeff KM, Stratos G, Campbell M, Cooke M, Jones HW III. Evaluation of the seminar method to improve clinical teaching. J Gen Intern Med 1986;1 (5):315-22.

7 Smith KL, Petersen DJ, Soriano R, Friedman E, Bensinger LD. Training tomorrow's teachers today: a national medical student teaching and leadership retreat. Med Teach 2007;29:328-34.

8 Eckstrom E, Homer L, Bowen JL. Measuring outcomes of a 1-minute preceptor faculty development workshop. J Gen Intern Med 2006;21 (5):410-4.

9 Furney SL, Orsini AN, Orsetti KE, Stern DT, Gruppen LD, Irby DM. Teaching the 1-minute preceptor: a randomised controlled trial. J Gen Intern Med 2001;16 (9):620-4.

10 Camp MG, Hoban JD, Katz P. A course on teaching for house officers. J Med Educ 1985;60 (2):140-2.

11 Meleca CB. A housestaff training programme to improve clinical teaching. Annu Conf Res Med Educ 1977;16:332-3.

12 Pristach CA, Donoghue GD, Sarkin R, Wargula C, Doerr R, Opila D, Stern M, Single G. A multidisciplinary programme to improve the teaching skills of incoming housestaff. Acad Med 1991;66 (3):172-4.

13 Roberts KB, DeWitt TG, Goldberg RL, Scheiner AP. A programme to develop residents as teachers. Arch Pediatr Adolesc Med 1994;148 (4):405-10.

14 Weissman MA, Bensinger L, Koestler JL. Resident as teacher: educating the educators. Med Educ 2006;40 (11): 1140 .

15 Wipf JE, Pinsky LE, Burke W. Turning interns into senior residents: preparing residents for their teaching and leadership roles. Acad Med 1995;70 (7):591-6.

16 Isaac S, Michael WB, eds. Handbook in Research and Evaluation for Education and the Behavioral Sciences, 3rd edn. San Diego, CA:EdITS 1995;97.

17 Mitchell M, Jolley J. Research Design Explained, 4th edn. Belmont, CA: Wadsworth Publishing 2001;437-43.

18 Steinert Y, Mann K, Centeno A, Dolmans D, Spencer J, Gelula M, Prideau D. A systematic review of faculty development initiatives designed to improve teaching effectiveness in medical education: BEME Guide No. 8. Med Teach 2006;28 (6):497-526.
19 Krathwohl DR. Methods of Educational and Social Science Research: an Integrated Approach, 2nd edn. New York, NY: Addison-Wesley Educational Publishers 1998;242.

20 Carney TF. Collaborative Inquiry Methodology.Windsor, ON: University of Windsor, Department of Instructional Technology 1990.

21 Miles MB, Huberman AM. Qualitative Data Analysis: an Expanded Sourcebook, 2nd edn. Thousand Oaks, CA: Sage Publications 1994.

22 Cohen J. Statistical Power Analysis for the Behavioral Sciences, 2nd edn. Hillsdale, NJ: Erlbaum Associates 1988.

23 University of Michigan Medical School. Meet the Dean University of Michigan Medical School. The mission of the Michigan Medical School. 2007. www.med.umich.edu/ medschool/dean/. [Accessed 7 January 2008.]

24 Dandavino M, Snell L, Wiseman J. Why medical students should learn how to teach. Med Teach 2007;29:558-65.

25 Billings-Gagliardi S, Barrett SV, Mazor KM. Interpreting course evaluation results: insights from think aloud interviews with medical students. Med Educ 2004;38 (10):1061-70.

26 Roberson L, Woolsey ML, Seabrooks J, Williams G. Data-driven assessment of teacher candidates during their internships in deaf education. Am Ann Deaf 2004;148 (5):403-12.

\section{SUPPORTING INFORMATION}

Additional supporting information may be found in the online version of this article:

Table S1. Programme schedule.

Please note: Wiley-Blackwell are not responsible for the content or functionality of any supporting materials supplied by the authors. Any queries (other than for missing material) should be directed to the corresponding author for the article.

Received 11 January 2008; editorial comments to authors 23 April 2008, 25 September 2008; accepted for publication 29 October 2008 